\title{
100 ANOS DE JORGE AMADO: O ESCRITOR, PORTUGAL E O NEORREALISMO, POR VANIA PINHEIRO CHAVES E PATRÍCIA MONTEIRO 100 ANOS DE JORGE AMADO: O ESCRITOR, PORTUGAL E O NEORREALISMO, BY VANIA PINHEIRO CHAVES AND PATRÍCIA MONTEIRO
}

\section{PATRICIA TRINDADE NAKAcOME*}

"omancista de putas e de vagabundos". É assim que Jorge Amado foi chamado por um crítico que desejava apontar a limitação da obra e também do autor em questão. Ao invés, porém, de tomar o rótulo como um xingamento, o autor baiano apropriou-se dele, orgulhando-se de ser aquele que retratava os mais despossuídos. Assim, o epíteto dá contornos à parte significativa da recepção de Jorge Amado, em que as escolhas estéticas (e também políticas) do autor são ao mesmo tempo mobilizadas para condená-lo ou exaltá-lo. É em diálogo com esse debate polarizado, entre o menosprezo de parte da crítica e a exortação de seus muitos leitores, que se insere 100 anos de Jorge Amado: o escritor, Portugal e o neorrealismo (CHAVES; MONTEIRO, 2015), que aqui resenhamos. O livro se inclina ao elogio a Jorge Amado, uma vez que celebra o centenário do autor, destacando o quanto leitores e amigos apreciavam sua obra. Além disso, há uma ampla avaliação crítica de sua produção literária, de tal modo a romper com alguns rótulos frágeis que o cercam. Trata-se de uma obra que, destaquemos, contém nove depoimentos, quatro conferências e quarenta e seis comunicações, as quais oferecem material para reflexão que em muito extrapola os limites desta breve resenha.

100 anos de Jorge Amado: o escritor, Portugal e o neorrealismo é um livro virtual que reúne os trabalhos apresentados na segunda etapa do Colóquio Internacional 100 anos de Jorge Amado, que se realizou inicialmente em Ilhéus, com o tema "História, Literatura e Cultura", e depois em Portugal, com o tema

\footnotetext{
* Professora Adjunta da Universidade de Brasília. Realizou pesquisa de pós-doutorado com bolsa PNPD na Universidade Federal de São Carlos (UFSCar) sobre a circulação da obra de Jorge Amado
} 
"O escritor, Portugal e o Neorrealismo", o qual enfocaremos aqui. A obra originada do evento português distingue-se pela sua abrangência, trazendo depoimentos, conferências e comunicações sobre o autor. Temos, assim, um painel amplo e diversificado acerca de Jorge Amado, abrangendo não apenas sua obra, mas também sua vida, personalidade. No caso desse escritor, é significativo que tenhamos acesso a essas informações, pois elas não apenas ilustram o conjunto de seus livros, mas antes iluminam uma forma de lê-los.

Diversos nomes apontam as qualidades pessoais de Jorge Amado, especialmente sua generosidade e humildade. Destaco aqui o depoimento de José Carlos de Vasconcelos, que, após fazer algumas colocações sobre a personalidade do escritor, questiona: "Mas, então, quando recordo Jorge Amado o que começa por me 'ocorrer' não é a sua obra? Claro que também é. Porém, como essa, a obra, está sempre à mão, não me pesa a sua ausência como pesa a do homem e do amigo" (VASCONCELOS, in CHAVES; MONTEIRO, 2015, p.75). Essa colocação exemplifica uma constante na primeira parte do livro, em que o lamento pela perda do autor sobrepõe-se à avaliação de sua vasta obra, não por limitações desta, mas pela força de uma personalidade que sempre buscava aglutinar e incentivar as pessoas. Nesse sentido, é interessante o depoimento do também escritor baiano Antônio Torres, assim iniciado: "Recordo Jorge Amado como um mestre também na arte de fazer amigos, apresentar pessoas umas às outras" (TORRES, in CHAVES; MONTEIRO, 2015, p.25). Torres relata que, por coincidência, seu primeiro livro seria lançado em São Paulo no mesmo dia de mais um lançamento do famoso escritor. Para sua surpresa, Jorge Amado, antes de ir para sua celebrada noite de autógrafos, foi à livraria onde o estreante estaria e comprou um livro, pedindo que ele fosse remetido autografado a seu hotel. Deixou ainda uma "cartinha simpática", com seu endereço e telefone para que os dois pudessem se encontrar posteriormente na Bahia, algo que ocorreu tempos depois. A partir disso, surge o questionamento: "Seria isso algo normal no mundo das letras, ou somente em se tratando de um cavalheiro chamado Jorge Amado?" (id., ibid., p. 27).

As cartas também ganham destaque no livro 100 anos de Jorge Amado: o escritor, Portugal e o neorrealismo. Elas revelam a personalidade atenciosa de Jorge Amado, disponível a todos que buscavam interlocução com ele. Isso pode ser notado no citado episódio de Antônio Torres, ou ainda, por exemplo, na colocação de Giovanni Ricciardi, que traça um belo depoimento sobre o autor e 
relembra que ele sempre respondia suas cartas: "Para mim, esse é um sinal extraordinário de sensibilidade e de amizade para com o remetente, qualquer remetente" (RICCIARDI, in CHAVES; MONTEIRO, 2015, p.70). Ricciardi indica que, de toda a correspondência que manteve com o autor, guardou apenas a carta em que ele agradecia pelo doutoramento em Bari, sendo as outras doadas à Fundação de Salvador. Essa indicação dá indícios do vasto material que existe a ser pesquisado nos arquivos de Jorge Amado, em uma correspondência que pode oferecer caminhos para uma compreensão mais profunda do autor e de sua obra, tal como já vemos no interessante trabalho de Silva (2006). Nessa linha, cabe destacar o trabalho de Antonio Dimas que integra o livro resenhado, no qual, ao investigar as cartas trocadas entre Jorge Amado e o escritor português Ferreira de Castro, são estabelecidas as relações do primeiro com a obra de Gilberto Freyre (DIMAS, in CHAVES; MONTEIRO, 2015).

As cartas podem ser uma profícua chave de leitura da obra amadiana, e é também uma carta que garante um dos pontos mais fortes de 100 anos de Jorge Amado: o escritor, Portugal e o neorrealismo. Trata-se de texto que Ondjaki dirige a Zélia Gattai, o qual, como lemos no título, é "seguido de P.S. a Jorge Amado" (ONDJAKI, in CHAVES; MONTEIRO, 2015). Nessa carta ficcional, o escritor angolano opta por uma abordagem diferenciada de todos os demais textos do livro, imaginando o sofrimento vivido por Zélia Gattai por conta do falecimento do marido. Ela, assim como vimos acontecer com Jorge Amado, é delineada em sua felicidade, tal como pôde ser apreendido por Ondjaki em sua leitura de $A$ casa do Rio Vermelho (GATTAI, 1999). Finda a parte do texto dedicada a Zélia, temos a continuação destinada a Jorge Amado, em que Ondjaki relata diversos episódios de sua vida em que não conseguia fazer com que as cartas por ele escritas chegassem aos seus destinatários. Em meio a esses tormentos, valeu-se, na adolescência, da carta que Guma enviara a Lívia em Mar Morto (2008) para ganhar o beijo de uma moça. Ele copiou a carta, sem nem retirar o nome de Lívia. Com essa carta, entregue em mãos, conseguiu o beijo da menina que já conhecia aquelas palavras, lidas há muitos anos no livro de Jorge Amado.

$O$ depoimento de Ondjaki adensa o que vimos em outros textos: o agradecimento de leitores a Jorge Amado por suas narrativas. São relatados episódios de leitores comuns que abraçam o autor, buscam seu conforto ou querem mudar o destino de personagens. Somam-se a eles relatos de leitores renomados, que encontraram estímulo, conforto e alegria nas obras do autor. É nesse aspecto 
que 100 anos de Jorge Amado: o escritor, Portugal e o neorrealismo se distingue de outros títulos que trazem estudos críticos sobre a obra de Jorge Amado. Há a emoção de leitores, de amigos, de companheiros do escritor baiano, o que dá um "tempero" especial a uma obra que trata de um autor também ele marcado por tantos gostos, cheiros e cores. Isso forma um valioso pano de fundo em que se prendem os diversos ensaios críticos integrantes da parte mais extensa do livro.

A obra traz textos de amigos e admiradores de Jorge Amado, mas há ali também o olhar do especialista, que busca distanciar-se da obra para poder analisá-la, revelando aspectos que não foram destacados pela crítica. Para ficar apenas entre os brasileiros, citemos Ana Maria Machado, que lançou um importante trabalho sobre o autor (2006) e no livro resenhado contribui com "Jorge Amado: uma leitura das leituras" (MACHADO, in CHAVES; MONTEIRO, 2015). A autora traça um amplo panorama da recepção crítica feita da obra amadiana, rastreando trabalhos publicados no Brasil e no exterior. Há o reconhecimento de que revisões contemporâneas estão conseguindo colocar em questão imagens cristalizadas do vasto conjunto de livros de Jorge Amado. Mas há a pesarosa constatação de que, no passado ou hoje, a crítica parece ter se esquivado daquilo que essencialmente norteia seu trabalho, ou seja, a leitura, tal como vemos indicado na conclusão de seu artigo: “O mínimo que se espera de uma crítica acadêmica é que leia o que o autor escreveu. E é isso o que, por vezes, a recepção de Jorge Amado em certos meios parece estar deixando de fazer" (id., ibid., p. 109).

Por partir de um congresso e por ser disponibilizado de forma gratuita e digital, o livro alcançou maior abrangência do que costumamos encontrar em outras publicações dedicadas ao autor. 100 anos de Jorge Amado: o escritor, Portugal e o neorrealismo aponta a necessidade de ler a vasta obra de Jorge Amado, inclusive trazendo estudos sobre a recepção do escritor no exterior. Ficamos sabendo como sua obra foi lida e traduzida, por exemplo, na Espanha, na Itália, na Polônia e França, sendo que, nesse caso, cabe destacar a análise de Glória Carneiro do Amaral sobre as afinidades entre Jorge Amado e Roger Bastide (BASTIDE, in CHAVES; MONTEIRO, 2015). Fora da Europa, temos ainda indícios de como Jorge Amado foi lido na África, como dão conta o depoimento do escritor Corsino Fortes sobre a literatura brasileira em Cabo Verde (FORTES, in CHAVES; MONTEIRO, 2015) e o artigo de Fabiana Carelli (CARELLI, in CHAVES; MONTEIRO, 2015), que aponta relações entre os Subterrâneos da liberdade (2011) e A vida verdadeira 
de Domingos Xavier (1988), de Luandino Vieira, o qual foi adaptado ao filme Sambizanga (1972), de Sarah Maldoror, estabelecendo uma relação política e estética entre Brasil e Angola.

Apenas a partir da breve listagem de artigos que tratam o diálogo que a obra amadiana estabeleceu em diferentes países, podemos notar que a grande variedade de textos de 100 anos de Jorge Amado: o escritor, Portugal e o neorrealismo extrapola os limites estabelecidos em seu título. Não teríamos sequer condições de enumerar as diferentes entradas para a compreensão da produção literária e da atuação ética e política de Jorge Amado indicadas no livro. São várias as perspectivas teóricas e vários os títulos eleitos para análise, muitos tratados em chave comparativa. Assim, para finalizar nosso texto, optamos por citar uma comunicação diretamente ligada ao tema do congresso que deu origem ao livro em questão. Trata-se do artigo de Edvaldo Bergamo, autor que é inclusive referência para outros textos por causa de importante livro que trata precisamente da relação entre Jorge Amado e o neorrealismo português (2008). $O$ autor colabora com "A 'nova descoberta do Brasil': a recepção crítica da obra de Jorge Amado na imprensa neorrealista Portuguesa" (BERGAMO, in CHAVES; MONTEIRO, 2015), em que aponta o motivo de o autor ter sido o que mais despertou interesse junto aos promotores do neorrealismo: "na sua simpatia humana mais patente expressa num estilo poético que toca a sensibilidade do leitor, além de uma peremptória confiança num futuro promissor, enunciada literariamente num otimismo inabalável" (id., ibid., 2015, p. 335).

Jorge Amado foi para leitores e amigos fonte de esperança e simpatia. E isso, como vimos, em muito extrapolou os limites de Portugal. Mas o país foi fundamental para manter vivo o legado de Jorge Amado, tanto se valendo dele no neorrealismo quanto, nos dias de hoje, sendo o lugar que aglutinou muitas pessoas para discutirem a obra do escritor baiano. Tal esforço se materializa no título resenhado, divulgando gratuitamente na Internet.

O livro organizado por Vania Pinheiro Chaves e Patrícia Monteiro abre caminhos para que a compreensão de Jorge Amado vá além de rótulos simplistas. 0 autor é orgulhosamente "romancista de putas e vagabundos". E é mais do que isso também. Cabe à crítica revisitar sua vasta obra, assumindo a tarefa essencial de lê-la, algo que, como pontuou Ana Maria Machado, parece ser por vezes negado a esse autor lido massivamente ao redor do mundo. A vasta publicação de Jorge Amado, como indicam as tantas leituras contidas em 100 anos de Jorge 
Amado: o escritor, Portugal e o neorrealismo, certamente, ainda oferece muito a ser pesquisado e discutido.

\section{Referências}

AMADO, Jorge. Mar morto. São Paulo: Companhia das Letras, 2008.

BERGAMO, Edvaldo. Ficção e convicção: Jorge Amado e o neo-realismo literário português. São Paulo: UNESP, 2008.

CHAVES, Vania Pinheiro; MONTEIRO, Patrícia (Orgs.) 100 anos de Jorge Amado: o escri-

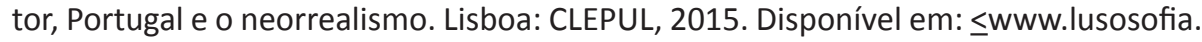
net/textos/ 20160215-chaves_vania_monteiro_patricia_100_anos_de_jorge_amado_2_.pdf>. Acesso em: 19 jul. 2018.

MACHADO, Ana Maria. Romântico, sedutor e anarquista: uma releitura de Jorge Amado. Rio de Janeiro: Objetiva, 2006.

SILVA, Márcia Rios da. O rumor das cartas: um estudo da recepção de Jorge Amado. Salvador: EDUFBA, 2006. 